\title{
Mediation role of cognitive regulation in predicting rumination based on distress tolerance in patients undergoing methadone maintenance therapy
}

\author{
Lida Aslanifar ${ }^{1}$, Sheida Sodagar ${ }^{2 *}$ iD , Maryam Bahrami Hidaji ${ }^{3}$ \\ 1. MA in Personality Psychology, Karaj Branch, Islamic Azad University, Karaj, Iran \\ 2. Assistant Professor of Health Psychology, Department of Psychology, Karaj Branch, Islamic Azad University, Karaj, Iran \\ 3. Assistant Professor of Psychology, Department of Psychology, Karaj Branch, Islamic Azad University, Karaj, Iran
}

Recieved: 10 Jan. 2018

Revised: 18 Jul. 2018

Accepted: 15 Aug. 2018

\section{Keywords}

Cognitive regulation

Distress tolerance

Methadone

Rumination

\section{Corresponding author}

Sheida Sodagar, Assistant Professor of Health Psychology, Department of Psychology, Karaj Branch, Islamic Azad University, Karaj, Iran

Email:Sh_so90@yahoo.com

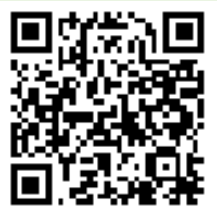

doi.org/10.30699/icss.21.2.41

\section{Abstract}

Introduction: The purpose of this study was to determine the mediation role of cognitive regulation in predicting rumination based on distress tolerance in patients undergoing methadone maintenance therapy.

Methods: The method of the current research was descriptive-correlational and the statistical population included all patients undergoing methadone maintenance therapy in the city of Tehran, Iran, in 2017. The data were analyzed using structural equation modeling.

Results: The results of this study showed that the indirect relationship between distress tolerance and rumination at with the mediating role of negative cognitive regulation was significant $(\mathrm{P}<0.01)$.

Conclusion: If people are not able to relieve these excitements, they will be overwhelmed by these thrilling excitements. In the meantime, cognitive emotion regulation is likely to play an essential role. Negative emotion strategies, each one due to its maladaptive nature, leads to exacerbations of negative emotions and may interact with rumination during the cognitive-emotional regulation process and result in increased rumination. 
(a)

\section{نقش ميانجى ترى نظمجويى شناختى در بيشبينى نشخوار فكرى بر اساس تحمل بريشانى در بيماران تحت درمان نكهدارنده متادون \\ ليدا اصلانى فر '، شيدا سوداكر r"id ، مريم بهرامى هيدجى"}

ا. كارشناس ارشد روانشناسى شخصيت، واحد كرج، دانشعاه آزاد اسلامى، كرج، ايران

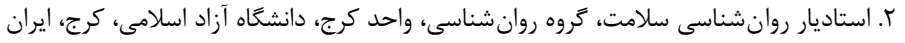

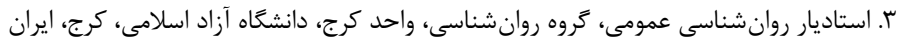

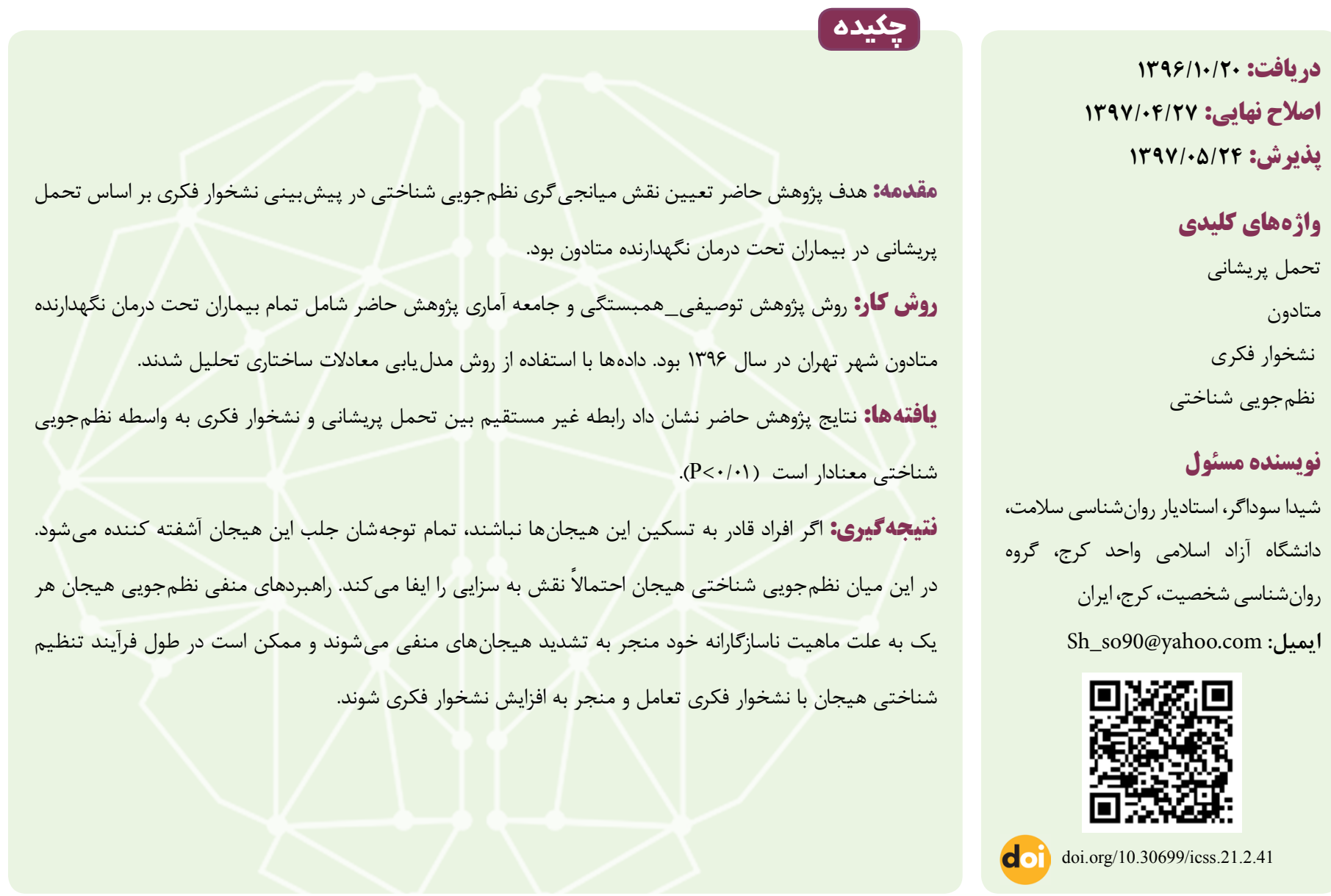

مقدمه

درازمدت، از اهميت قابل ملاحظهاى برخوردار است و امروزه توجه شايانى به آن مىشود (أl). اعتياد يا سوءمصرف مواد به عنوان معضلى فردى و و اجتماعى، كانون توجه متخصصين در حوزههاى مختلف قرار گرفته است. عوامل متعددى در شروع و تداوم مصرف مواد دخالت دارند. يزوهش هاى بسيارى به نقش هيجانات در رَايش به سوءمصرف مواد اشاره نمودهاند.
اعتياد به مواد، داراى ابعاد مختلف بوده و منجر به تخريب بالينـ مشخص و يا ناراحتى مىشود (1). اعتياد به مواد يا هر فعاليت ديخرى عميقاً مى تواند كارايى عملكرد، سلامت و شادكامى افراد را تحت تأثير قرار دهد و گاهى به مشكلات جدى اجتماعى منجر گردد (r، ؟). توجه به ييامدهاى انواع روشهاى يرهيز از مواد مانند درمان نتخهدارنده متادون در 
ديدكاه) با برخى رفتارهاى يرخطر (راندگى خطرناك، خشونت، سيكار كشيدن، مصرف مواد، مصرف الكل، دوستى با جنس مخالف) رابطه منفى دارد، همجنين دو راهبرد ناسازگارانه (سرزنش ديخران و تلقى فاجعهآميز) با رفتارهاى يرخطر ياد شده رابطه مثبتى را نشان دادند.

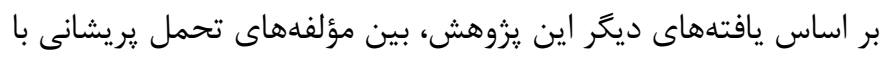

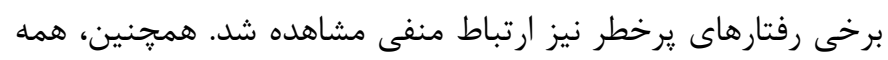

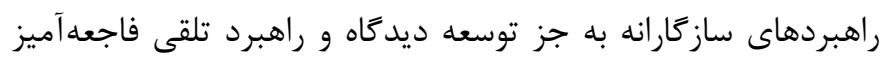

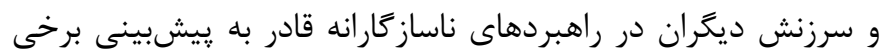
رفتارهاى يرخطر بودند. از طرفى از بين مؤلفههاى تحمل يريشانى، ارزيابى و جذب پيشبينى كننده برخى از رفتارهاى يرخطر را بودند

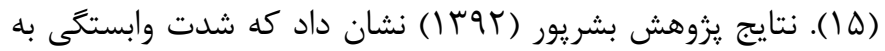
مواد با سرزنش خود و سرزنش ديگران رابطه مثبت دارد، همجنين ولع مصرف نيز با سرزنش خود، نشخوار فكرى، تلقى فاجعهآميز، كنترل

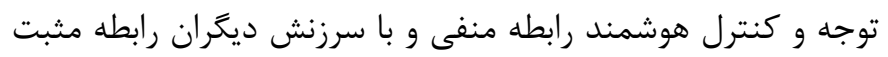

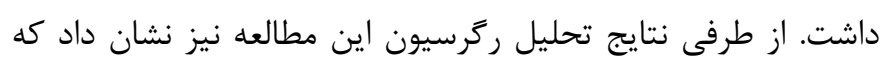

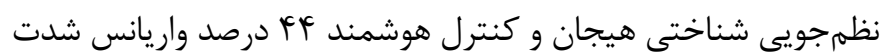
وابستخى و DV درصد از واريانس ولع مصرف را تبيين مى كنند (1) (1). بر اساس نظريههاى خود نظهمويى، رفتارها در موقعيت هاى اجتماعى بر اساس سه مؤلفه شناختى: معيارها، خود نظارتى و خود ارزيابى در

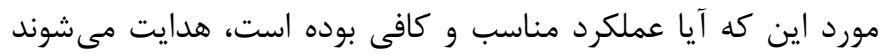
(IV) نشخوار فكرى، با فرآيندهاى حاكم بر شناخت از جمله تمايلات خود نظارتى غير سودمند همراه است (1)). فقدان توانايى در هدايت توجه، به مشكلات شايع متعددى منجر مى شود كه شامل ناتوانى در

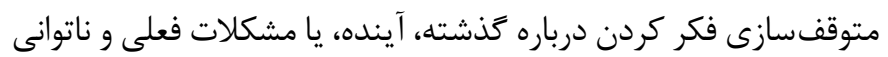

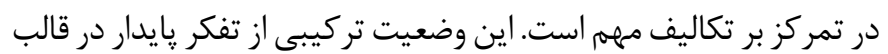
نشخوار فكرى و نكرانى در رفتارهاى كنار آمدن ناكارآمد مثل اجتناب است (9 (). نشخوار فكرى افكار و رفتارهايى است كه به طور مكرر توجه نائ شخص را بر احساسات منفىاش و همجنين بر ماهيت و مفاهيم ضمنى اين احساسات از جمله دلائل، مفاهيم، و يِامدهاى احساسات معطوف

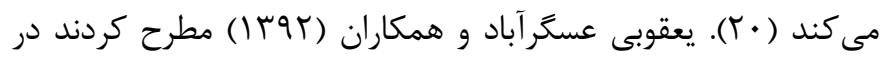

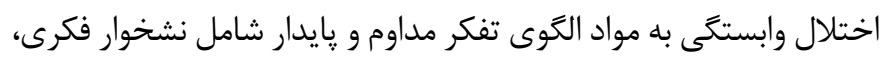

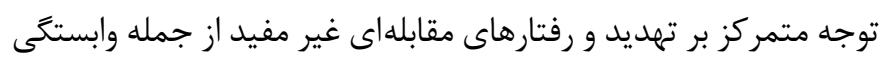

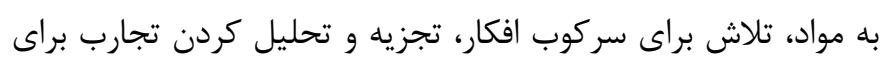

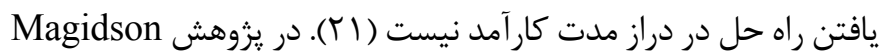

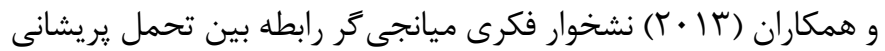
و نشانهاى افسردگى در مصرف كنندههاى مواد بود (TT). هر رفتار اعتيادى ممكن است در نتيجه نشانهاى روان يزشكى به وجود
سطح يايين تنظيم هيجانى كه ناشى از ناتوانى در مقابله مؤثر با هيجانها و مديريت آنهاست در شروع مصرف مواد نقش دارد. دشوارى در مديريت هيجان ها وشكل در تحمل يريشانى از مشكلات افراد سوءمصرف كننده

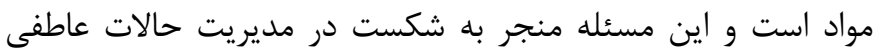

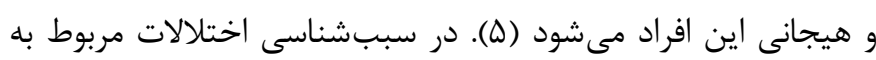

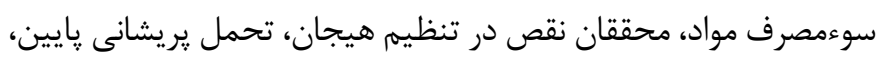
رفتار بدون تفكر و نشخوار فكرى را ذكر نمودهاند (؟). تحمل بريشانى، تمايل و توانايى باقى ماندن و رفتار كردن به طور مثبت و خوددارى از دركير شدن در رفتارهاى ناسازگًارانه در طول دورههاى نمايل تنشهاى جسمانى و هيجانى است (V). بر اساس مدل طرحوارههاى هيجانى افراد در صورت ارزيابى منفى هيجانها به اين نتيجه مىرسند

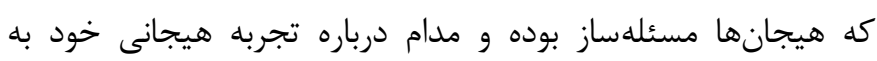

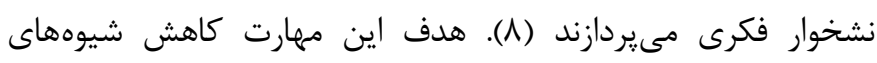

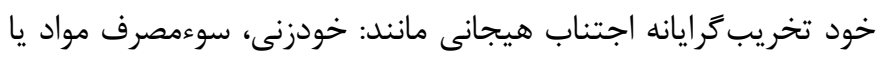

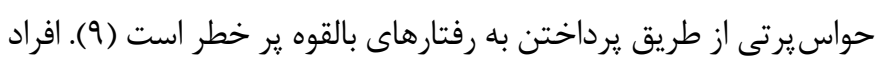

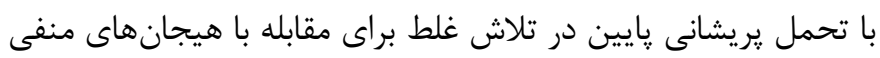

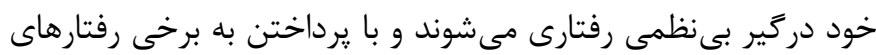
مخرب مانند مصرف مواد درصدد تسكين درد هيجانى خود بر مى آيند

نظهمجويى شناختى هيجان Cognitive emotion regulation به عنوان راهبردهاى شناختى براى پاسخ به حوادث تنشزا و مديريت اطلاعات برانگيزننده هيجانى تعريف شده است و بخشى از مقابله شناختى محسوب مىشود (1)). به عقيده Garnefski و همكاران

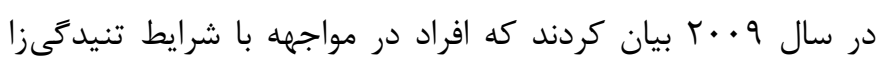
از راهبردهاى تنظيم هيجانى متنوعى مانند راهبردهاى منفى شامل: نشخوار فكرى، سرزنش خود، سرزنش ديخران، تلقى فاجعهآميز و راهبردهاى مثبت شامل تمركز مجدد مثبت، ارزيابى مثبت مجدد، يذيرش، تمركز مجدد بر برنامهريزى، توسعه ديدكاه اشاره كرد (با()). يزوهش ها نشان دادهاند راهبردهاى ناساز گارانه تنظيم شناختى هيجان بران

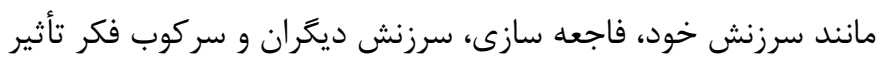

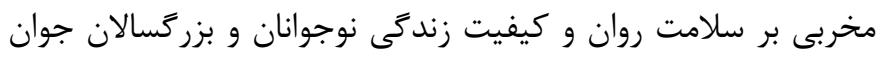

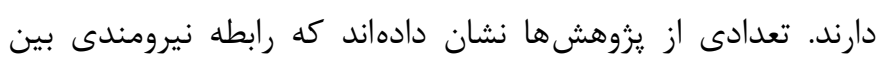

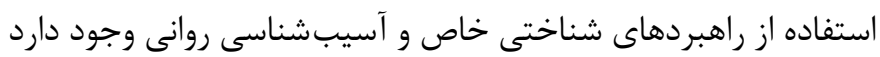

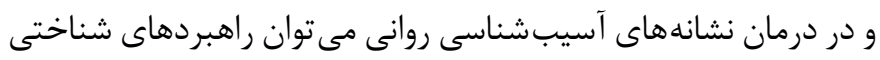

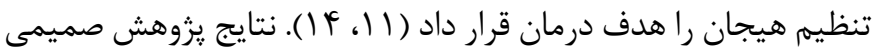
و همكاران (هو 1) نشان داد كه راهبردهاى ساز كارانه (يذيرش، تمركز مجدد مثبت، تمركز مجدد بر برنامهريزى، ارزيابى مثبت و توسعه 
و انتخاب شركت كنند كان با توجه به ملاك هاى ورود و خروج از يزوهش

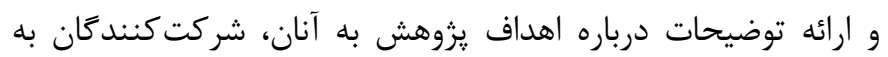

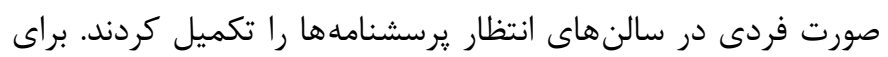

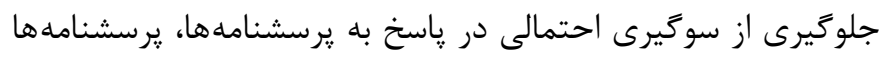

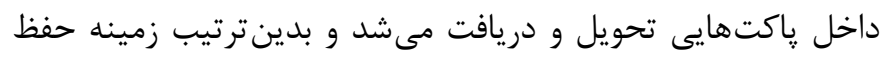

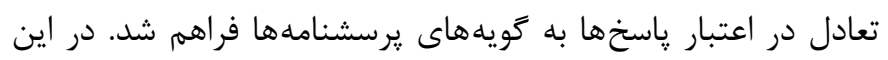
يزوهش ملاحظات اخلاقى شامل اخذ رضايت آكاهانه، تضمين حريم

\section{خصوصى و رازدارى رعايت شد.}

يرسشنامه نشخوار فكرى: يرسشنامه نشخوار فكرى توسط يوسفى رأن

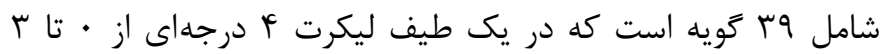

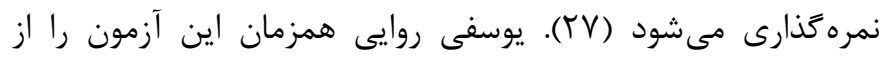

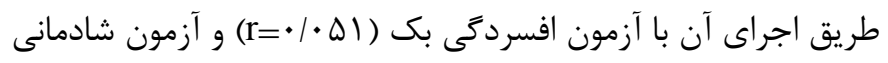

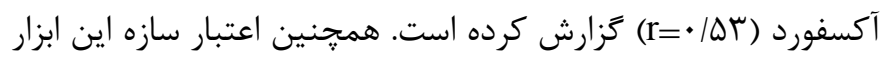
از طريق تحليل عاملى به روش واريماكس انجام شده، اعتبار افتراقى از از

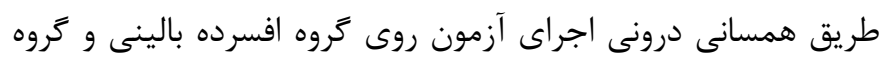

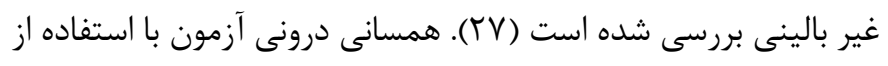

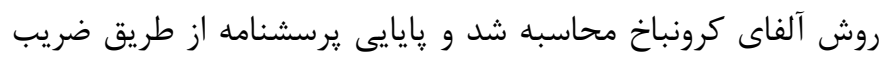

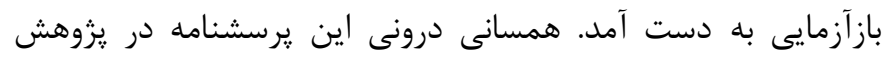

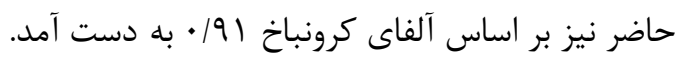

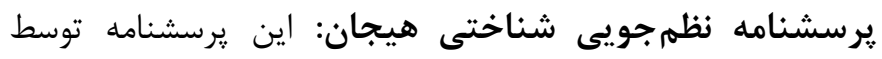
Garnefski

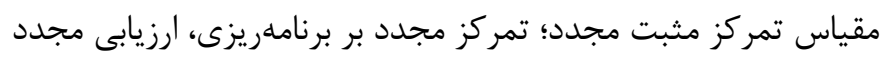

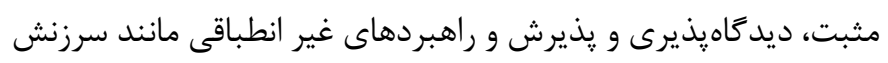

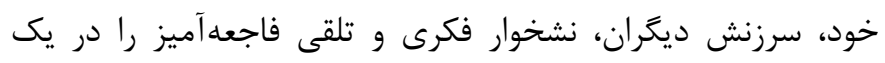

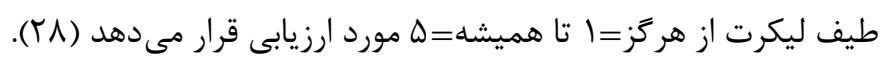

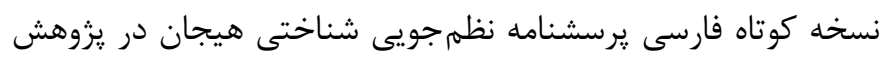

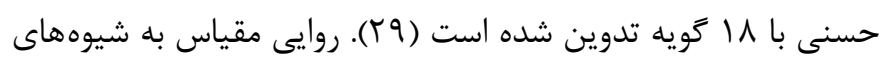

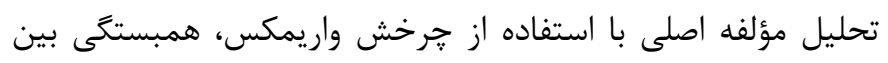

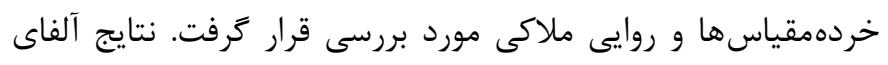

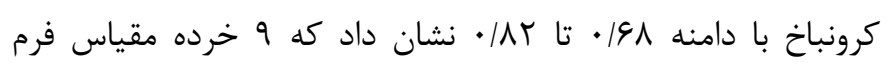
كوتاه نسخه فارسى يرسشنامه نظه جويى شناختى هيجان داراى اعتبار

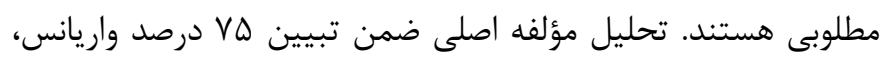

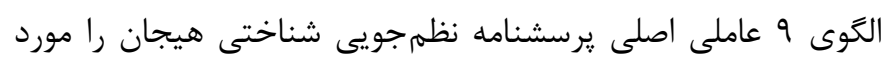

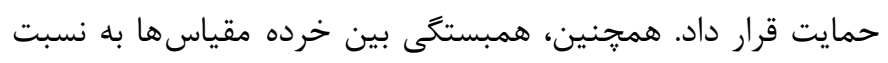

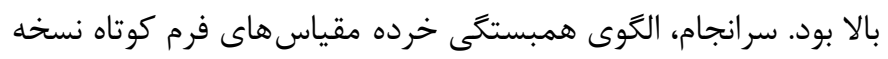
فارسى يرسشنامه نظمجويى شناختى هيجان با نشانه هاى افسردى لنى

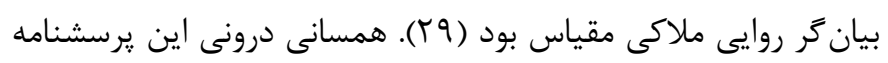

آيد و يا منجر به بروز نشانه هاى روان يزشكى شود (سT). به نظر مى رسد

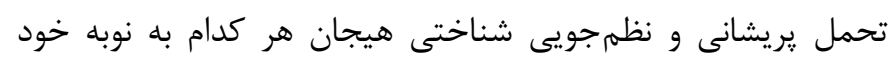

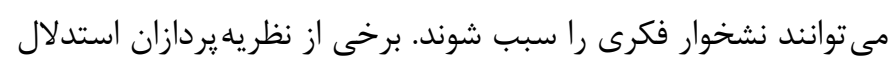

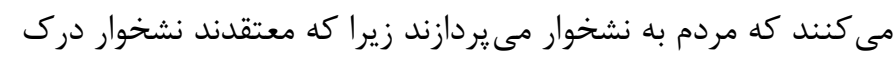

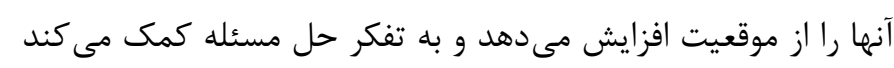

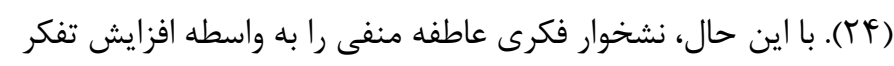

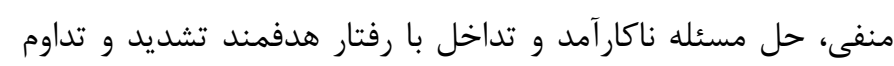

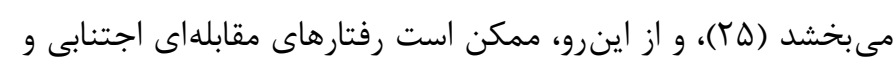

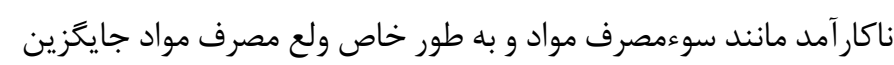

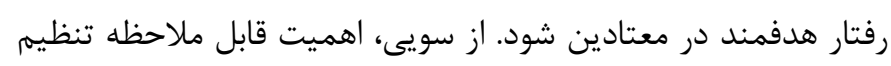
هيجانى در آسيبشناسى روانى معتادين برجسته نشده است. ميىتوان

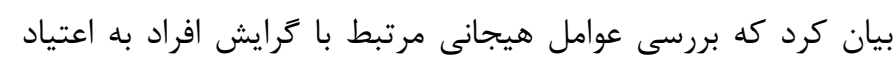

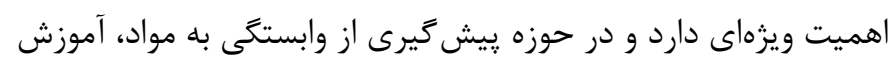

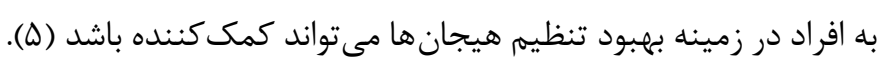

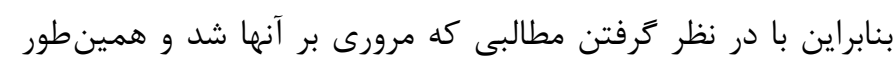

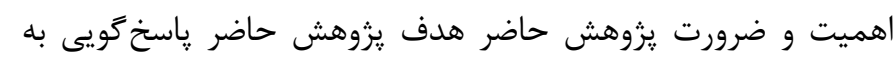

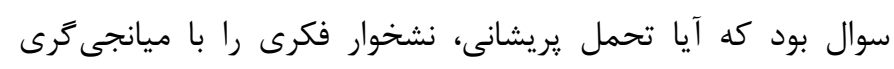

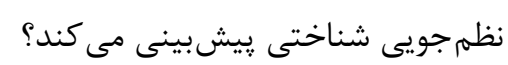

\section{روش كار}

روش يزوهش توصيفى از نوع همبستخى و جامعه آمارى يزوهش

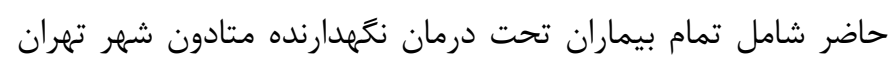
در كلينيكهاى نيكان و راه سبز و مركز ملى مطالعات اعتياد در بهار

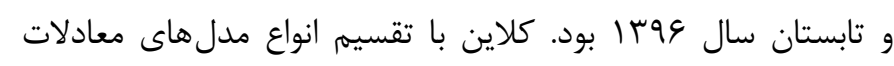

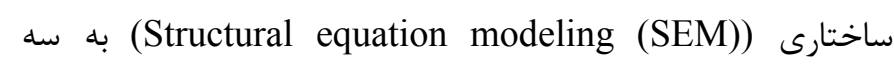
نوع ساده، كمى بيجيده و بيجيديده عنوان مى كند كه حجم نمونه در

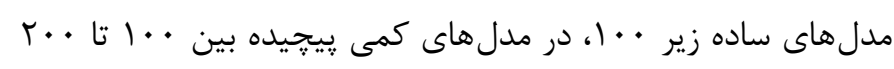

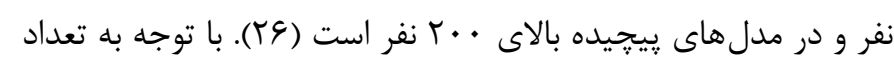

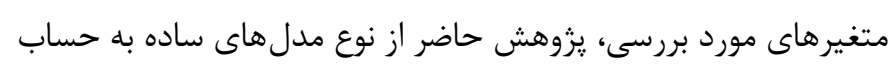

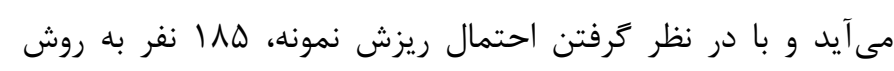

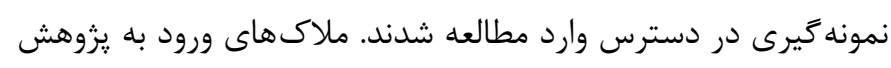

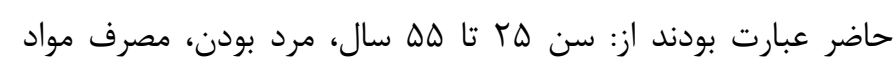

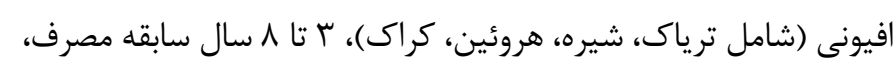

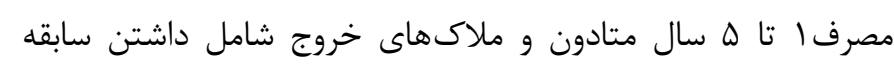

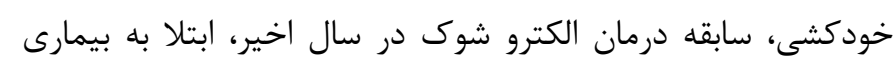

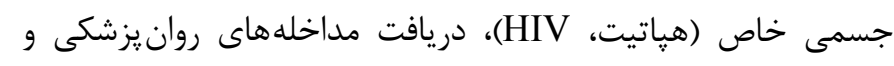

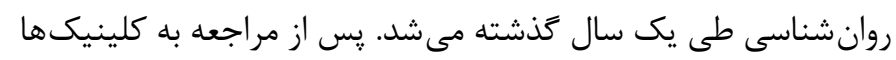


صورت منفى و در سطح معنادارى | • • با نشخوار فكرى همبسته است. همجنين بعد منفى نظمجويى شناختى به صورت مثبت و در سطح | • • • با نشخوار فكرى همبسته بود. در مقابل بين بعد مثبت نظم_جويى شناختى و نشخوار فكرى همبستكى معنادارى ملاحظه نشد. ييش از يرداختن به مدليابى معادلات ساختارى، مفروضههاى اين تحليل مانند ارتباط بين متغيرها در جهار جوب ماتريس همبستغى، مفروضه نرمال بودن توزيع دادهاى تك متغيرى (مقادير كشيدكى و جولتى) و ارزيابى مفروضه همخطى بودن (عامل ضريب تحمل و تورم واريانس) مورد بررسى قرار گرفت. كلاين توصيه مى كند كه به منظور ارزيابى مفروضه نرمال بودن شكل توزيع دادهها در يزوهش هاى با حجم نمونه بالاتر از • 1 از شاخصهاى جولكى و كشيدگى استفاده شود (צ'). او معتقد است در صورت كه مقادير كشيدگى و جولخى در محدوده r" باشد توزيع

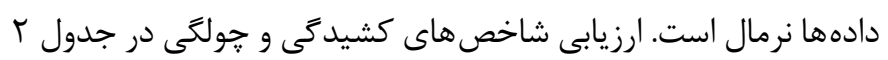
نشان مى دهد كه توزيع دادههاى تك متغيرى در يزوهش حاضر نرمال است، زيرا كه شاخصهاى مربوط به جولكى و كشيدگى هيج كدام از متغيرهاى يزوهش خارج از محدود r土 نيست. همجنين ارزيابى مقادير ضريب تحمل و تورم واريانس نشان مى دهد كه مفروضه همخطى بودن در بين متغيرهاى پيشبين برقرار است. زيرا كه ضريب تحمل و تورم واريانس متغيرهاى بيشبين به ترتيب بزرگتر از | / • و كوجى تر از • بود (Iا)). يكى ديگر از مفروضههاى تحليل مدليابى معادلات ساختارى، نرمال بودن توزيع جندمتغيرى است، ترسيم منحنى توزيع نمرههاى فاصله نشان داد كه تركيب متغيرهاى ييشبين در تبيين
در يزوهش حاضر نيز بر اساس آلفاى كرونباخ VD/ • به دست آمد. مقياس تحمل يريشانى: مقياس تحمل يريشانى توسط Simons و Gaher

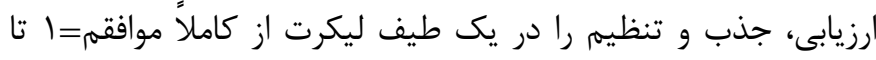
كاملاً مخالفم=ه مورد ارزيابى قرار مى دهد. گويه

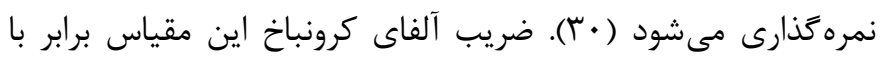

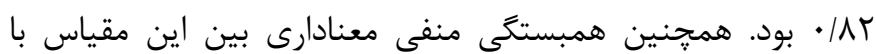

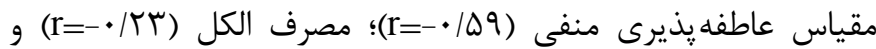
مارى جوانا (• r=-•/r) و همبستخى مثبت معنادارى را بين اين ابزار با مقياس عاطفه يذيرى مثبت (r=/r/) وجود دارد ( • (r). همسانى درونى اين يرسشنامه در يزوهش حاضر نيز بر اساس آلفاى كرونباخ س// • به دست آمد.

\section{1. 1.}

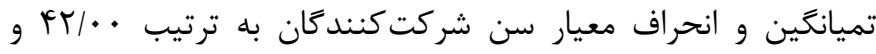

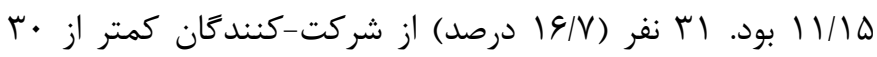
سال، فT نفر (ז/F

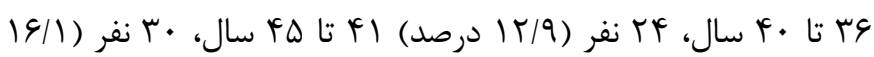

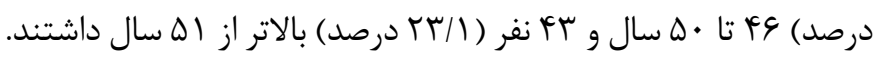

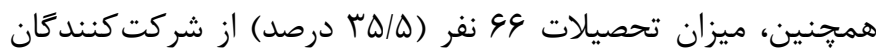

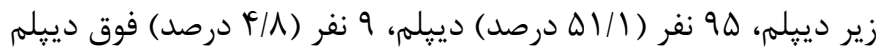
و 19 نفر (N/9 درصد) كارشناسى يا بالاتر بود. بر اساس ماتريس همبستخى متغيرهاى يزوهش (جدول () روابط در جهات مورد انتظار است، به طورى كه همه مولفه هاى تحمل يريشانى به

جدول ا. ماتريس همبستخى متغيرهاى يزوهش

\begin{tabular}{|c|c|c|c|c|c|c|}
\hline نشخوار فكرى & شناختى منفىى & شناختى مثبت & تنظيم & ارزيابى & تحمل & متغير \\
\hline & & & & & تنظيم & شناختى مثبت \\
\hline & & & & - & نشخوار فكرى & شناختى منفى \\
\hline & & & - & $\cdot / \uparrow \wedge \varepsilon * * *$ & •/ & تنظيم \\
\hline & & - & $\cdot / 11 \Delta_{*}$ & $\cdot / \mu 10 * * * *$ & $\cdot / r \Lambda \mid * * *$ & تنظيم شناختى مثبت \\
\hline & - & $-\cdot 11 \cdot 9$ & $-\cdot / \cdot \wedge r$ & $-\cdot / F \mid \mathcal{F} \Delta * *$ & $-\cdot / \wedge F_{*}$ & تنظيم شناختى منفى \\
\hline- & $\cdot 10 \cdot 9$ 絭米 &.$- / 111$ & $-\cdot / r \cdot 1 * * *$ & $-\cdot / r V V$ 类米 & $-\cdot / 1 \Delta \Delta *$ & نشخوار فكرى \\
\hline
\end{tabular}


جدول r. كشيدگى، جولتىى، ضريب تحمل و تورم واريانس متغيرهاى يزوهش

\begin{tabular}{|c|c|c|c|c|}
\hline تورم واريانس & ضريب تحمل & كشيدتى & جولكى & متغير \\
\hline $1 / Q \wedge \varphi$ & .194. & $-\cdot r \cdot r$ & $\cdot / 4 M \Lambda$ & تحمل \\
\hline $1 / 91 \Delta$ & $\cdot 10 \cdot 4$ &.$- / T T \Delta$ & 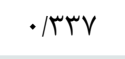 & ارزيابى \\
\hline (ז/r/ & . IVGY & $-\cdot|9| V$ & $\cdot \mid r G 4$ & تنظيم \\
\hline $1 / 1 \Lambda$. & $\cdot \mid A F A$ & $-\cdot / \cdot \wedge \mathrm{V}$ & $.1 . r F$ & تنظيم شناختى مثبت \\
\hline $1 / 111$ & - / 194 &.$- / . T t$ & $-\cdot / K \varepsilon V$ & تنظيم شناختى منفى \\
\hline متغير ملاك & متغير ملاك & $-\cdot / F \wedge F$ & . / KF & نشخوار فكرى \\
\hline
\end{tabular}

مشاهده شده آن بود. از آنجا كه متغير مكنون تحمل يريشانى داراى سه

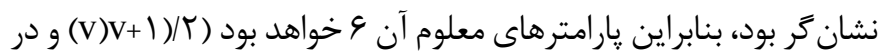

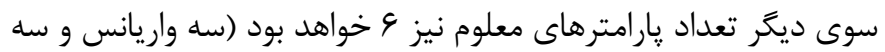
ضريب مسير). بنابراين انتظار مىرود درجه آزادى در مدل اندازهيرى برابر با صفر باشد (در مدليابى معادلات ساختارى درجه آزادى حاصل

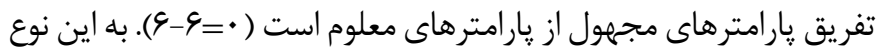

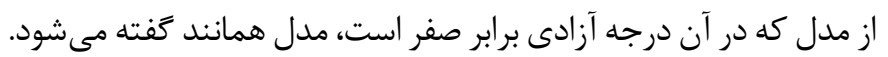

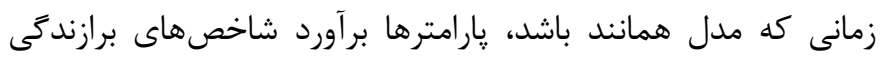

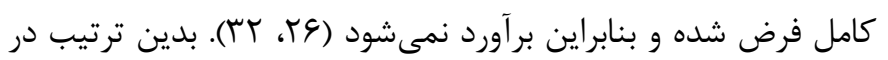

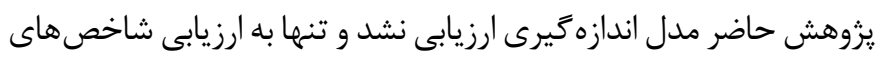
برازند مدى مدل كلى اكتفا شد.

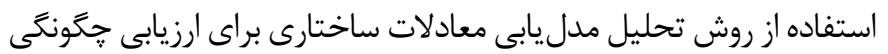
برازش مدل يزوهش با دادهاى كردآريى شده نشان داد كه مدل برازش قابل قبولى با دادهها ندارد (جدول ؟). منطبق بر انتظار شاخص مجذور كاى برى

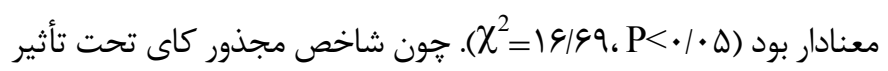
حجم نمونه قرار دارد، ديخر شاخصهاى برازندگى مورد بررسى قرار كرفت

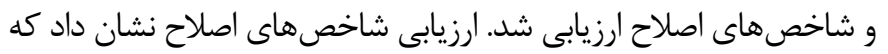

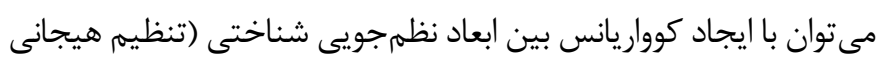

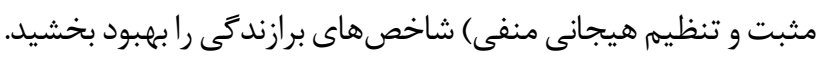

متغير ملاك نرمال است. مفروضه ديكر تحليل ركرسيون، خطى بودن

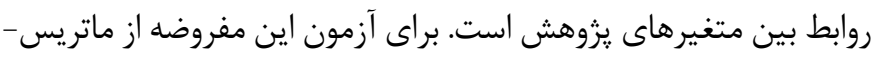

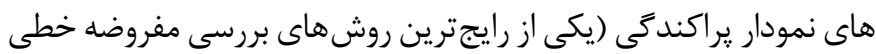
بودن روابط بين متغيرها) استفاده شد. استفاده از ماتريسهاى نماى نمودار يراكندگى نشان داد كه متغيرهاى يزوهش حاضر دو به به دو نمودار يراكندگى ايجاد كردهاند كه به شكل بيضى است. بر اين اساس هيج كئ كدام

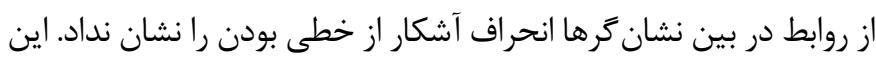

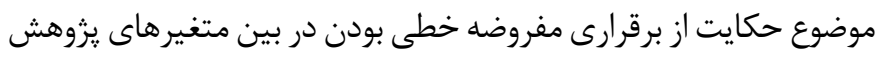

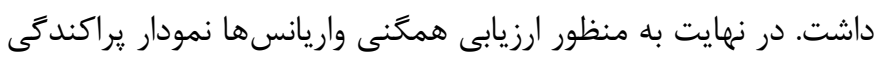

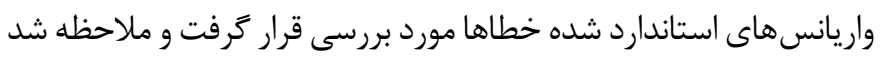

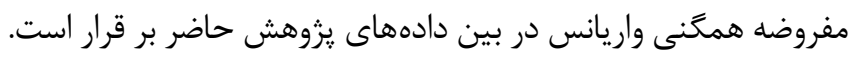

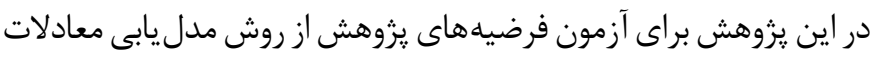
ساختارى استفاده شده است. اين روش بسط مدل خطى كلى است و از دو بخش مهم تشكيل شده است: مدل اندازهيرى و مدل ساختارى. به

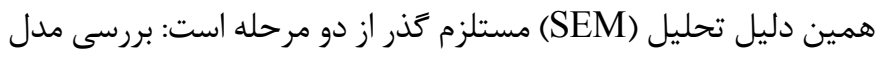

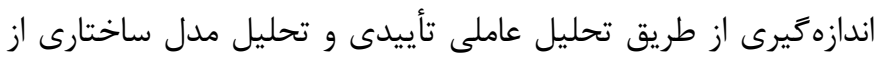

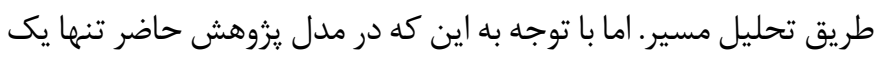

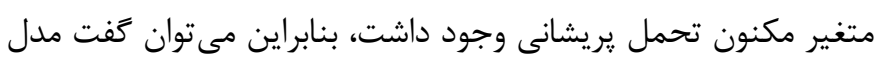

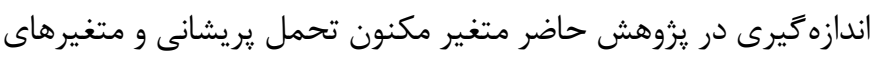

جدول r. شاخص هاى برازندگى مدل اوليه و مدل اصلاح شده

\begin{tabular}{|c|c|c|c|c|c|c|}
\hline CFI & AGFI & GFI & RMSEA & $\chi^{2} / \mathbf{d f}$ & $\chi^{2}$ & شاخصهاى برازندكى \\
\hline$\cdot / 909$ & .1911 & $.19 V r$ & $\cdot 1 \cdot 19$ & r/rAF & 19199 & مدل اوليه \\
\hline .199. & $\cdot / 94 \wedge$ & .1910 & $\cdot / \cdot \hat{k V}$ & $|/ 4| V$ & $\Lambda / \Delta \cdot$ & مدل اصلاح شده در مرحله اول \\
\hline$<\cdot 19$. & $<\cdot / 9$ & $<\cdot 19$ & $<\cdot / \cdot \wedge$ & $<r$ & $\mathrm{P}>\cdot / \cdot \Delta$ & نقاط برش قابل قبول (اr) \\
\hline
\end{tabular}


Kenny و به كار گرفته شد تا نقش منحصر به فرد هر يك از دو متغير ميانجى معين شود. بر اساس نتايج جدول ه رابطه غير مستقيم بين تحمل يريشانى و

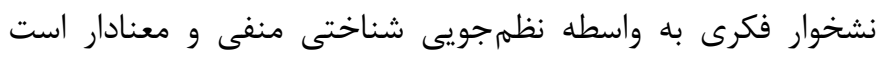

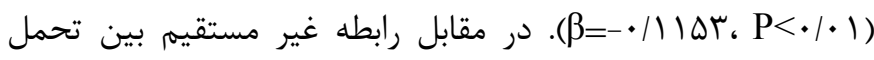

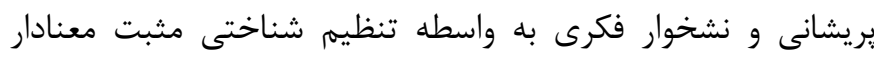
نيست( ) (
جدول \& نشان مى دهد كه ضريب مسير غير مستقيم بين متغير مكنون تحمل يريشانى و متغير مشاهده شده نشخوار فكرى منفى و معنادار

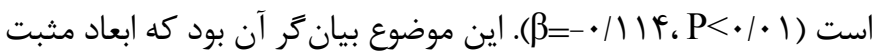
و منفى نظمجويى شناختى به صورت منفى و معنادار رابطه بين متغير

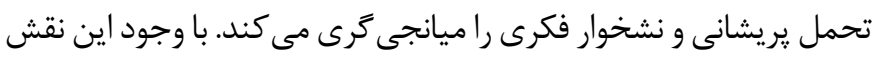

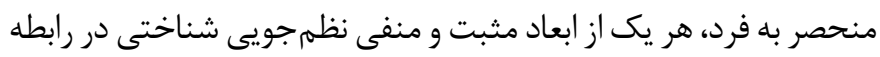

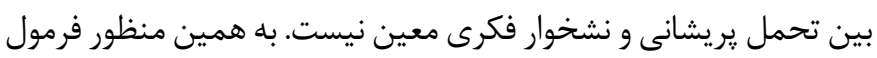

جدول أ. ضرايب مسير كل و مستقيم و غير مستقيم بين متغيرهاى بروهش در مدل ساختارى

\begin{tabular}{|c|c|c|c|c|}
\hline $\mathbf{P}$ & $\boldsymbol{\beta}$ & S.E & $\mathbf{b}$ & 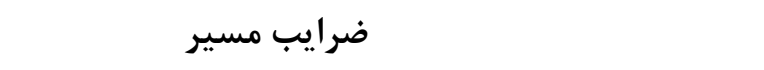 \\
\hline$\cdot / \cdot 1$ & $-\cdot / T \Delta F$ & $\cdot /$ TVG & $-\cdot / \wedge V r$ & تحمل يريشانى × تنظيم شناختى منفى \\
\hline $.1 . .1$ & rre & $\cdot / T \Delta V$ & $1 / \cdot v V$ & تحمل پريشانى × تنظيم شناختى مثبت \\
\hline.$/ \cdot 1$ & $\cdot / F \Delta F$ &.$/ 191$ & $1 / 4 \wedge 9$ & نظم جويى شناختى منفى † نشخوار فكرى \\
\hline$\cdot / r+1$ & $-\cdot / \cdot \wedge \wedge$ & . Tra & $-\cdot / r \Lambda F$ & نظم جويى شناختى مثبت † نشخوار فكرى \\
\hline $.1 . .9$ & $-\cdot \pi r$. &.$/ 99 \vee$ & - T/QTA & ضريب مسير مستقيم تحمل يريشانى † نشخوار فكرى \\
\hline$\cdot \cdot \cdot r$ & $-\cdot / l f F$ & r & $-1 / 819$ & ضريب مسير غير مستقيم تحمل بريشانى \ نشخوار فكرى \\
\hline.$/ . \cdot 1$ & $-\cdot / \wedge \Delta \Delta$ & $1 / \cdot v 1$ & $-r / \cdot \psi v$ & ضريب مسير كل تحمل يريشانى † نشخوار فكرى \\
\hline
\end{tabular}

جدول ه. ضرايب مسير غير مستقيم تحمل يريشانى و نشخوار فكرى بر اساس نقش ميانجى گر ابعاد نظمجويى شناختى

$\begin{array}{llllllllll}Z & \text { SEab } & \beta & \text { a*b } & \text { SEb } & \text { b } & \text { SEa } & \text { a } & \end{array}$

\begin{tabular}{|c|c|c|c|c|c|c|c|c|}
\hline$-r / \Lambda V * *$ & . IFTHD & - & $-1 / T 19$ & .1191 & $1 / \% \wedge 9$ & . ITVG & $-\cdot / \Lambda V^{\prime}$ & تحمل يريشانى نظم ٪ \\
\hline $1 / 14$ & $\cdot / r V \cdot r$ & .1 .494 & $\cdot / \mu \cdot \Delta \Lambda$ & . & $\cdot / T \wedge F$ & $\cdot / r \Delta V$ & $1 / \cdot V V$ & 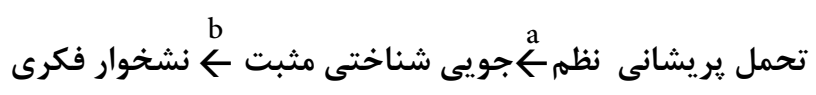 \\
\hline
\end{tabular}

شكل 1. مدل ساختارى در تبيين رابطه بين نظمجويى شناختى، تحمل بريشانى و نشخوار فكرى در بيماران تحت درمان نكهدارنده متادون 
شديدتر و وحشتناكتر از واقعيت آن واقعه ادراك و ابراز مى كند (Y^). احتمالاً افرادى كه رويدادهاى ناراحت كننده را فاجعهبار تلقى مى كنند، منفعلانه آن را مى يذيرند (૧ (1). راهبردهاى منفى نظم جويى هيجان هر يك به علت ماهيت ناساز گارانه خود منجر به تشديد هيجان هاى منفى مى شوند و ممكن است در طول فرآيند تنظيم شناختى هيجان با نشخوار فكرى تعامل و منجر به افزايش نشخوار فكرى شوند. راهبرد تنظيم شناختى هيجان نشخوارگرى شكلى از تفكر تكرارى كزءار درباره نشانهای ״ريشانى و دلائل، معانى ضمنى، و پيامدهاى آن است. مدل فراشناختى نشخوار فكرى را به مثابه راهبرد مقابلهاى ارادى و فعالانه، شامل افكار تكرارى، براى مقابله با هيجان و رويدادهاى تهديد كننده، در نظر مى گيرد. بر اساس مدل فراشناختى، اين نوع تفكر، راهبردى است كه با هدف خودتنظيمى، توسط رويدادهاى درونى مانند افكار و هيجانهاى منفى برانخيخته مىشود. نشخوار فكرى به تداوم ابهام و ناهمخوانى بين آن جه فرد مى بداند، منجر مىشود. بهعلاوه، نشخوار فكرى موجب فعالسازى و تدوام احساس تهديد شده و به اين ترتيب عاطفه منفى را براى مدت طولانى تداوم مىبخشد. اين فرآيند منابع توجهى با ارزش را مصرف كرده و تصميم گيرى و تفكر روشن و كنترل شده در موقعيتهاى ير فشار را مختل مى سازند. درگير شدن مكرر در فرآيند نشخوار فكرى، نيرومندى اين قبيل ياسخهاى عادتى را افزايش مى دهد، در نتيجه، آكاهى فرد از اين فعاليتها كاهش يافته و به آنها اجازه مى آدهد تا بدون هرگونه ارزيابى ادامه يابند. نيرومندى عادت و فقدان آكَاهى، به احساس از دست دادن كنترل بر اين فرآيند ذهنى منتهى مى شود. همجنين نشخوار فكرى مى تواند در ساير فرآيندهاى خودتنظيمى شناختى نيز تداخل

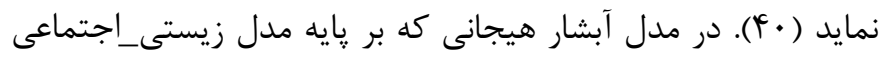

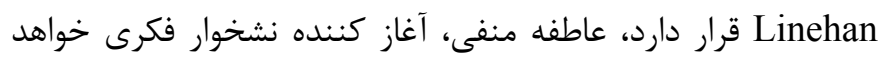
بود، كه اين خود منجر به تشديد عاطفه منفى و نشخوار فكرى بيشتر خواهد شد. نشخوار فكرى قابليت تشديد انواع هيجانهاى منفى از جمله غم، ترس و خشم را دارد و تجربه اين هيجانها را طولانى تر مى سازد. اين جرخه ممكن است يك ياسخ عاطفى تقويت شده را حتى در برابر محركهاى هيجانى ناجيز توليد كند، علاوه بر اين، اين جرخه خود را تداوم مىبخشد به طورى كه ممكن است براى مدت زمان طولانى دوام آورد ( أl). اين جرخه معيوب تجربه ناخوشايند شديدى از هيجان هاى منفى و نشخوار فكرى (آبشار هيجانى) را ايجاد مى كند، كه مى تواند منجر به رفتارهاى آشفته شديدى نظير خودزنى، استفاده از

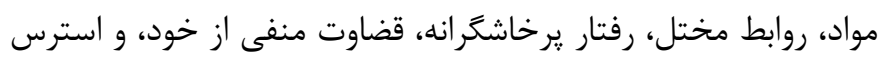

نتايج يزوهش حاضر نشان داد بر خلاف بعد مثبت نظمه جويى شناختى بعد منفى آن به صورت منفى و معنادار رابطه بين تحمل يريشانى و نشخوار فكرى رادر بيماران تحت درمان نكَهدارنده متادون ميانجى گرى مى كند. نتايج حاصل از اين يزوهش با نتايج حاصل از يزوهشهاى

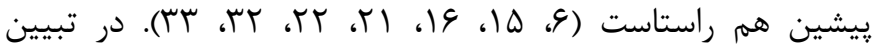
يافته هاى حاصل از يزوهش حاضر مىتوان گفت گر جه تحمل يريشانى ممكن است حاصل فرآيندهاى فيزيكى و شناختى باشد، اما بازنمايى آن به صورت حالت هيجانى است كه اغلب با تمايل به عمل جهت رهايى از تجربه هيجانى مشخص مىشود. افراد داراى تحمل يريشانى يايين، هيجان را غير قابل تحمل مى دانند و نمى توانند به آشفتگى و ״ريشانى شان رسيدگى كنند، اين افراد وجود هيجان را نمى يذيرند و از وجود آن احساس شرم و آشفتگى مى كنند زيرا توانايى هاى مقابلهاى خود با هيجان ها را دست كم مى گيرند. ديخر مشخصه عمده تنظيم هيجانى افراد با تحمل آشفتگى يايين، تلاش فراوان اين افراد براى جلو گيرى از هيجان هاى منفى و تسكين فورى اين هيجان هاست. لازم به ذكر است كه اگر اين افراد قادر به تسكين اين هيجان ها نباشند، تمام توجهشان جلب اين هيجان آشفته كننده مىشود و عملكردشان به طور قابل ملاحظهاى كاهش مى يابد (• ()). در اين ميان نظمج جويى شناختى

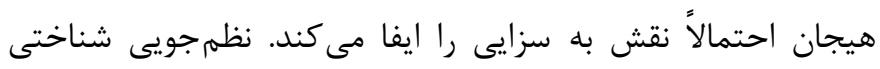
هيجان مى تواند به عنوان توانايى فرد براى انتقال هيجان و يا طرحريزى احيى كردن سازوكار مدارا براى مديريت هيجان در نظر گرفته شود (هऍ). شناختها يا فر آيندهاى شناختى به افراد كمك مى كند كه هيجانها و و احساسهاى خود را تنظيم نموده و توسط شدت هيجان ها مغلوب نشود (Y9). راهبردهاى نظمهويى شناختى هيجان به افراد كمك مى كند تا برانخيختخى و هيجان هاى منفى را تنظيم نمايند (عَ). افرادى كه راهبردهاى غير مؤثر تنظيم هيجان را فرا گرفتهاند ممكن است بيش از ديخران مستعد استفاده از رفتارهاى يرخطر به عنوان ابزارى براى تسكين هيجان منفى باشند (rV). برخى از نظريه يردازها استدلال مى كنند كه مردم به نشخوار فكرى مى يردازند زيرا كه معتقدند نشخوار فكرى درك آنها را از موقعيت افزايش مى دهد و به تفكر حل مسئله كمك مى كند (YY). با اين حال، نشخوار فكرى افسردگى را به واسطه افزايش تفكر منفى، حل

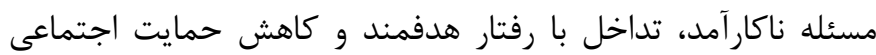
تشديد و تداوم مىبخشد (WD). سرزنش خود به مقصر دانستن خود و سرزنش ديگران به مقصر دانستن ديگران يا محيط از واقعه پيش آمده كفته مى شود (^^). در راهبرد فاجعه يندارى فرد شرايط ايجاد شده ران 
سوال ها ياسخ نداده باشند و از اين رو يِيشنهاد مىشود در يزوهش هاى آتى از ابزارهاى ديخر نظير مصاحبه نيز استفاده شود.

\section{نتيبجه كيرى}

بر اساس يافته هاى حاصل از يزوهش حاضر عدم تحمل يريشانى احتمالاً مى تواند منجر به تفكر نشخوارى و هوس مصرف در مصرف كنند متادون شود. بنابراين، پيشنههاد مىشود، در كاهش عدم تحمل يريشانى در مصرف كنندگان/سومصرف كنندگان نظم جويى شناختى هيجان به اين افراد آموزش داده شود. با توجه به آسيبشناسى اعتياد و بهره گيرى اين بيماران از بعد منفى نظمجويى هيجان در عوض بعد مثبت آن ييشنهاد مى شود درمان نظمجويى شناختى هيجان به عنوان درمان مكمل در كنار متادون درمانى براى اين بيماران به كار گرفته شود. همجنين، در درمان سوءمصرف/مصرف مواد/الكل علاوه بر متادون از درمانهايى كه نشخوار فكرى، راهبردهاى تنظيم شناختى هيجان و تحمل «ريشانى را هدف قرار مى دهند بهره گرفته شود.

\section{تشكر و قفرواذى}

با سياس از يرسنل محترم مركز ملى مطالعات اعتياد بويزه جناب آقاى دكتر محمدرضا حدادى كه امكان و بستر لازم براى تكميل

$$
\text { يرسشنامه ها را در آن مركز فراهم نمودند. }
$$

\section{References}

1. Khakpour M, Afrooz G, Ghanbari Hashemabad B, Rejaee A, Ghobari bonab B, Mehrafarid M. Predicting of severity of addiction from temperament and character features in individuals with drug addiction. Journal of North Khorasan University of Medical Sciences. 2016;8(2):257-269. (Persian)

2. Zhu Y, Zhang H, Tian M. Molecular and functional imaging of internet addiction. BioMed Research International. $2015 ; 2015: 378675$

3. Chen L, Nath R. Understanding the underlying factors of internet addiction across cultures: A comparison study. Electronic Commerce Research and Applications. 2016;17:38-48.

4. Beygi A, Mohammadyfar MA, Farahani MN, Mohammadkhani S. The comparative study of coping styles and hope
يس از حادثه شود. اين رفتارهاى آشفته توجه را از عاطفه منفى و افكار نشخوارى منحرف مى كند. به نظر مى رسد متغيرهايى نظير فاجعهسازى نَرانى، سركوب فكر و تحمل يريشانى يايين در طول آبشار هيجانى با نشخوار فكرى تعامل كنند و منجر به حفظ يا تشديد آبشار هيجانى شوند. سركوب فكر نه تنها منجر به نشخوار فكر نمى شود، بلكه تلاش

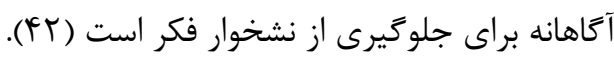
در تبيين عدم بيشبينى معنادار بعد مثبت نظهمجويى شناختى هيجان شايد بتوان كفت با توجه به اين كه نمونه يزوهش حاضر را بيماران تحت درمان تشكيل مى دادند و با توجه به ماهيت بيمارى اعتياد كه با نشخوار فكرى و بعد منفى نظهمويى شناختى هيجان در ارتباط است بعد مثبت نظهمجويى شناختى هيجان در اين بيماران بسيار كم رنگ بوده و اين بيماران به دليل ماهيت بيمارى خود بسيار از بعد منفى نظمجويى هيجان بهره مى گيرند. هر يروهشى اخر جه در ماهيت به دئ دنبال ارتباط بين عوامل و ميزان تأثير آن است، به هر حال در بطن خود يكى مجنى مجموعه

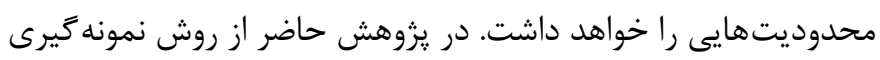
در دسترس براى جمعآورى دادهها استفاده شده كه اين امر تعميم يافته هاى يزوهش حاضر را محدود مى سازد. همجنين در يزوهش حاضر از ابزار خودگزارشى جهت جمعآورى دادهها استفاده شد و از آنجا كه نمونه مورد بررسى بيماران تحت درمان با متادون بودند اين احتمال

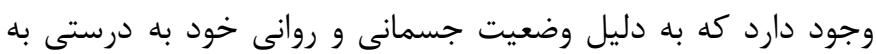

among narcotic anonymous and methadone maintenance treatment members. Research on Addiction. 2012;5(20):55-72. (Persian)

5. Najafi M, Mohammadifar M, Abdollahi M. Emotional dysfunction and tendency to substance abuse: the role of emotion regulation, distress tolerance and sensation seeking. Social Health and Addiction. 2015;2(5):53-68.

6. Taimory S, Ramezani F, Mahjob N. The effectiveness of mindfulness-based group cognitive therapy in reducing depression and obsessive rumination among women under methadone treatment. Research on Addiction. 2015;9(34):145-159.

7. Daughters SB, Lejuez CW, Bornovalova MA, Kahler CW, Strong DR, Brown RA. Distress tolerance as a predictor of early 
treatment dropout in a residential substance abuse treatment facility. Journal of Abnormal Psychology. 2005;114(4):729-734.

8. Leahy RL, Napolitano LA, Tirch D. Emotion regulation in psychotherapy: A practitioner's guide. New York:Guilford press;2011.

9. Fassbinder E, Schweiger U, Martius D, Brand-de Wilde O, Arntz A. Emotion regulation in schema therapy and dialectical behavior therapy. Frontiers in Psychology. 2016;7:1373.

10. Esmaeilinasab M, Andami Khoshk A, Azarmi H, Samar Rakhi A. The predicting role of difficulties in emotion regulation and distress tolerance in students' addiction potential. Research on Addiction. 2014;8(29):49-63.

11. Potthoff S, Garnefski N, Miklósi M, Ubbiali A, Domínguez-Sánchez FJ, Martins EC, et al. Cognitive emotion regulation and psychopathology across cultures: A comparison between six European countries. Personality and Individual Differences. 2016;98:218-224.

12. Garnefski N, Koopman H, Kraaij V, Ten Cate R. Brief report: Cognitive emotion regulation strategies and psychological adjustment in adolescents with a chronic disease. Journal of Adolescence. 2009;32(2):449-454.

13. Samani S, Sadeghi, L. Psychometric properties of the cognitive emotion regulation questionnaire. Psychological Models and Methods. 2011;1(1):51-62.

14. Izadpanah S, Schumacher M, Arens EA, Stopsack M, U1rich $\mathrm{I}$, Hansenne $\mathrm{M}$, et al. Adolescent harm avoidance as a longitudinal predictor of maladaptive cognitive emotion regulation in adulthood: The mediating role of inhibitory control. Journal of Adolescence. 2016;52:49-59.

15. Samimi Z MF, Hasani J, Zakeri MM. The Role of Cognitive Emotion Regulation Strategies and Distress Tolerance in High-Risk Behaviors among Students. Journal of Behavioral Sciences. 2016;14(1):92-102. (Persian)

16. Basharpoor S. Relationship of emotional cognitive regulation and intelligent control with severity of dependence and craving in people with drug dependence. Research on Addiction. 2014;7(28):131-146. (Persian)
17. Ghanbari S, Javaheri A, Seyed Mousavi PS, Melhi E. Relationship between dimensions of perfectionism in university students and their positive relations with others. Journal of Applied Psychology. 2011;4(4):72-84. (Persian)

18. Hashemi Z, Mohammad Aliloo M, Hashemi Nosratabad T. The effectiveness of metacognitive therapy on major depression disorder: A case report. Journal of Clinical Psychology. 2010;2(3):85-97. (Persian)

19. Mahmoudalilou M, Sharifi M. Borderline personality disorder: Therapy and management. Tehran:Arjmand;2013. (Persian)

20. Nolen-Hoeksema S. Responses to depression and their effects on the duration of depressive episodes. Journal of Abnormal Psychology. 1991;100(4):569-582.

21. Yaghobi Asgharabad E, Bassak Nejad S, Mehrabi Zadeh Honarmand M, Zamiri Nejad S. Effectiveness of metacognitive therapy (MCT)on depressed addicts under methadone maintenance treatment (MMT) in Mashhad, Iran. Journal of North Khorasan University of Medical Sciences. 2013;5(1):167-174. (Persian)

22. Magidson JF, Listhaus AR, Seitz-Brown CJ, Anderson $\mathrm{KE}$, Lindberg B, Wilson A, et al. Rumination mediates the relationship between distress tolerance and depressive symptoms among substance users. Cognitive Therapy and Research. 2013;37(3):456-465.

23. Floros G, Siomos K, Stogiannidou A, Giouzepas I, Garyfallos G. Comorbidity of psychiatric disorders with Internet addiction in a clinical sample: The effect of personality, defense style and psychopathology. Addictive Behaviors. 2014;39(12):1839-1845.

24. Papageorgiou C, Wells A. Positive beliefs about depressive rumination: Development and preliminary validation of a self-report scale. Behavior Therapy. 2001;32(1):13-26.

25. Nolen-Hoeksema S, Wisco BE, Lyubomirsky S. Rethinking rumination. Perspectives on Psychological Science. 2008;3(5):400-424.

26. Kline RB. Principles and practice of structural equation 
modeling. 2nd ed. New York \& London:Guilford press;2005.

27. Yosefi Z. Investigating and comparing the effectiveness of attention education on reducing rumination in depressed and obsessive patients in Isfahan. [MSc Thesis]. Isfahan:University of Isfahan;2005. (Persian)

28. Garnefski N, Kraaij V, Spinhoven P. Negative life events, cognitive emotion regulation and depression. Personality and Individual Differences. 2001;30(8):1311-1327.

29. Hasani J. The psychometric properties of the cognitive emotion regulation questionnaire (CERQ). Journal of Clinical Psychology. 2010;2(3):73-84. (Persian)

30. Simons JS, Gaher RM. The distress tolerance scale: development and validation of a self-report measure. Motivation and Emotion. 2005;29(2):83-102.

31. Meyers LS, Gamest G, Goarin AJ. Applied multivariate research: Design and interpretation. London \& New Delhi:Sage publication;2006.

32. Ho R. Handbook of univariate and multivariate data analysis and interpretation with SPSS. London \& New York:Chapman \& Hall/CRC;2006.

33. Ghaedniay Jahromi A, Nouri R, Hasani J, Farmani Shahreza $\mathrm{S}$. The effectiveness of group training of procedural emotion regulation strategies in cognitive coping of individuals suffering substance abuse. Research on Addiction. 2015;8(31):71-90. (Persian) 34. Nadimi M. On the effectiveness of group dialectical behavior therapy in the enhancement of distress tolerance and emotional regulation in substance abusers. Research on Addiction. 2016;9(36):141-160. (Persian)

35. Supplee LH, Skuban EM, Shaw DS, Prout J. Emotion reg- ulation strategies and later externalizing behavior among European American and African American children. Development and Psychopathology. 2009;21(2):393-415.

36. Ghasemzade Nassaji S, Peyvastegar M, Hosseinian S, Mutabi F, Banihashemi S. Effectiveness of cognitive-behavioral intervention on coping responses and cognitive emotion regulation strategies in women. Journal of Behavioral Sciences 2010;4(1):35-43. (Persian)

37. Borjali A, Aazami Y, Chopan H, Arab Quhistani D. Effectiveness of emotion regulation strategies for aggression control based on gross model in substance abusers. Iranian Journal of Rehabilitation Research in Nursing. 2015;2(1):53-65. (Persian) 38. Garnefski N, Kraaij V. The cognitive emotion regulation questionnaire. European Journal of Psychological Assessment. 2007;23(3):141-149.

39. Salehi A. Mazaheri Z, Aghajani Z, Jahanbazi B. The role of cognitive emotion regulation strategies in the prediction of depression. Knowledge \& Research in Applied Psychology. 2015;16(59):108-117. (Persian)

40. Wells A. Metacognitive therapy for anxiety and depression. New York \& London:Guilford press;2009.

41. Aftab A, Karbalaee Mohammad Meigouni, Taghiloo S. The mediating role of emotion regulation strategies in the relationship between borderline personality and conjugal violence . Journal of Applied Psychology. 2015;8(4):7-27. (Persian) 42. Selby EA, Joiner TE, Jr. Cascades of emotion: The emergence of borderline personality disorder from emotional and behavioral dysregulation. Review of General Psychology. 2009;13(3):219-229. 